\title{
Estudo do desenvo/vimento neuropsicomotor de crianças nascidas prematuras
}

\author{
Gleizy Berticelli', Cinara Freitas Henker², Patrícia Oliveira Roveda³ ${ }^{3}$ Valéria Neves Kroeff Mayer ${ }^{4}$
}

\begin{abstract}
RESUMO
Este estudo teve como objetivos identificar possíveis déficits no desenvolvimento neuropsicomotor (DNPM) de crianças pré-termo matriculadas em Escolas Municipais de Educação Infantil em Santa Cruz do Sul - RS, e elaborar um folder direcionado a pais/cuidadores e educadores, contemplando orientações de posicionamentos e atividades para as crianças nas suas diferentes fases de desenvolvimento. Participaram da pesquisa crianças nascidas até a $37^{\text {a }}$ semana de gestação, que no momento do estudo estavam entre $04^{\circ}$ e $24^{\circ}$ mês de vida, e que não apresentavam síndrome genética, lesão neurológica ou alteração ortopédica decorrentes da prematuridade. Os pais das cinco crianças selecionadas responderam um questionário, e a avaliação motora foi realizada através do Teste de Triagem de Desenvolvimento de Denver II. Os resultados demonstraram que todos os sujeitos avaliados possuíam DNPM adequado à sua faixa etária. Desta forma, os folders foram entregues com o intuito de que estas crianças continuem sendo estimuladas corretamente, nos ambientes domiciliar e escolar.
\end{abstract}

Descritores: Desenvolvimento Infantil; Prematuro; Fisioterapia.

\section{Study of neuropsychomotor development in children born prematurely}

\begin{abstract}
This study aimed to identify possible deficits in neuropsychomotor development of preterm children enrolled at Municipal Elementary Schools in Santa Cruz do Sul-RS, and elaborating a folder to parents/caregivers and educators, contemplating positioning and activities guidelines for the children in their different development phases. The participants of de research were children born up to 37 weeks of pregnancy, at the time of the study were between the $4^{\text {th }}$ and $24^{\text {th }}$ month of life and who had no genetic syndrome, neurological or orthopedic injury changes resulting from prematurity. The parents of the five selected children answered a questionnaire, and the motor evaluation was performed using the Denver Developmental Screening Test II. The results showed that all subjects tested had suitable for their age group neurodevelopment. In this way, the folders were delivered in order that these children continue to be properly stimulated, at home and school environments.
\end{abstract}

Descriptors: Child Development; Premature; Physical Therapy.

\footnotetext{
1,2 Acadêmica de Fisioterapia na Universidade de Santa Cruz do Sul (UNISC), Santa Cruz, RS, Brasil.

${ }^{3}$ Mestre em Hidrocinesioterapia pela Universidade Tuiuti do Paraná (UTP), Curitiba, PR, Brasil.

${ }^{4}$ Mestre em Educação Especial pela Universidade de Santa Cruz do Sul (UNISC), Santa Cruz, RS, Brasil.
} 


\section{Introdução}

A Organização Mundial da Saúde (OMS) define como pré-termo o lactente nascido com menos de 37 semanas de idade gestacional. Usando os dados do Sistema Nacional de Nascidos Vivos (SINASC), pesquisadores de doze universidades brasileiras em 2011, revelaram que 11,8\% das crianças nascidas no Brasil foram prematuras, sendo que até 0 ano de 2010, este índice era de 7,1\% $\%^{1,2}$. 0 aumento do percentual de bebês nascidos pré-termo nos últimos anos aponta não somente para a necessidade de medidas preventivas para investigar e reduzir os fatores de risco que levam à prematuridade, como também uma atenção especial a estas crianças, seus familiares, cuidadores e educadores.

A prematuridade é decorrente de circunstâncias diversas e muitas vezes imprevisíveis, em todos os lugares e classes sociais. Alguns autores identificaram como situações que possivelmente favorecem a prematuridade: o útero oligodrâmnio, a ruptura prematura de membranas amnióticas, pré-eclâmpsia, sífilis e descolamento prematuro da placenta ${ }^{3}$. Outros apontaram também o tabagismo, diabetes gestacional, infecção do trato geniturinário, ausência de acompanhamento pré-natal, alimentação materna (antes e durante a gestação) e uso de álcool e outras drogas ${ }^{4,5,6}$.

Devido principalmente à imaturidade dos sistemas neurológico e motor das crianças nascidas pré-termo, há uma tendência que estas apresentem um atraso no Desenvolvimento Neuropsicomotor (DNPM), se comparadas aos nascidos a termo. Por isso, na equipe multidisciplinar que acompanha o lactente desde os seus primeiros meses de vida, a presença do profissional fisioterapeuta faz-se necessária para avaliar e estimular a aquisição dos marcos motores adequados a cada fase de desenvolvimento, bem como para orientar pais, cuidadores e educadores sobre posicionamentos e atividades de intervenção precoce, para evitar ou diminuir possíveis déficits no DNPM. Muitas vezes, a superproteção por parte dos adultos, por considerarem o prematuro um ser mais frágil, acaba também limitando um pouco sua interação com o ambiente, fator extremamente necessário para o desenvolvimento de suas habilidades sensório-motoras \$ $^{4,7,8,9,10}$.

ODNPM sofre suas maiores mudanças nos primeiros anos de vida, tempo em que as etapas fundamentais e importantes são atingidas e quando ocorrem as maiores aquisições de conhecimentos e habilidades sensório-motoras, que permitem à

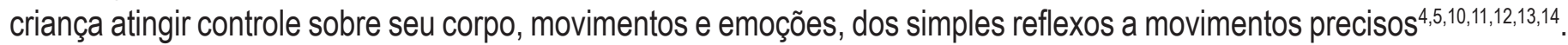
"As diferenças individuais entre as crianças são muitas, inclusive características físicas, temperamento e personalidade; mas a sequência de desenvolvimento é bastante previsível"15:23.

Diversos autores consideram a avaliação do desenvolvimento como um dos aspectos fundamentais na atenção à saúde da criança, pois trata-se de um processo contínuo de coleta e organização de informações importantes para compreensão de atrasos, planejamento e implementação de tratamentos efetivos ${ }^{8,14}$.

Para a realização da avaliação do DNPM, deve-se destacar a importância do uso de escalas confiáveis, que tenham sua sensibilidade e especificidade comprovada ${ }^{5,7}$. No Brasil, um dos testes mais utilizados nos estudos acerca do desenvolvimento da criança pré-termo é o Teste de Triagem de Desenvolvimento de Denver II (TTDD II), o qual foi utilizado neste estudo7.

A temática desta pesquisa torna-se pertinente e de grande relevância para a comunidade em geral, devido aos crescentes índices de nascimentos de bebês prematuros no Brasil e no mundo. Além disso, outro aspecto importante a considerar é o aumento do tempo diário de permanência das crianças nas Escolas Municipais de Educação Infantil (EMEls), que atualmente deixaram de ter um caráter meramente assistencialista e tornaram-se também fundamentais na educação e estimulação do DNPM dos lactentes, juntamente com pais e cuidadores.

Diante do exposto, o presente estudo teve como objetivos identificar possíveis déficits no DNPM de crianças nascidas pré-termo matriculadas em EMEls, e elaborar um manual com um programa direcionado a pais, cuidadores e educadores, contemplando orientações de posicionamentos e atividades para as crianças nas suas diferentes fases de desenvolvimento.

\section{Metodologia}

O presente estudo caracteriza-se como qualitativo de delineamento observacional exploratório de grupo, compondo uma amostra não probabilística do tipo intencional ${ }^{16}$.

A coleta de dados ocorreu em maio de 2014, após a obtenção do Parecer Consubstanciado do Comitê de Ética em Pesquisa da UNISC (CEP UNISC), sob n 544.317, aprovado em 27/02/14, seguindo os preceitos de ética em pesquisa com seres humanos, de acordo com a Resolução CNS/MS 466/12. 
Este trabalho foi desenvolvido em quatro EMEls da cidade de Santa Cruz do Sul - RS, mediante autorização concedida através de Carta de Aceite assinada pela Secretaria Municipal de Educação e Cultura (SMEC) e consentimento da Direção das escolas.

Como critérios de inclusão, determinou-se que poderiam participar da pesquisa crianças nascidas pré-termo, de ambos os sexos, que estivessem entre o quarto e o vigésimo quarto mês de vida, nascidos de gestações únicas ou múltiplas, de qualquer etnia, devidamente matriculadas em uma das EMEls selecionadas, e cujos pais ou responsáveis aceitassem participar da pesquisa. Seriam excluídas do estudo as crianças que não se enquadrassem nos critérios de inclusão ou que apresentassem diagnóstico clínico de alguma síndrome genética, lesão neurológica ou alteração ortopédica não decorrentes da prematuridade.

Foi constatado que nos registros da criança nas EMEls não havia a informação a respeito da prematuridade, sendo assim, foi enviada aos pais uma breve circular divulgando o estudo e questionando a idade gestacional (em semanas) de cada criança. Foram enviadas 239 circulares, das quais foram respondidas 68, e apenas 6 foram definidas pelos pais como nascidas prematuras. Após, foram agendadas entrevistas presenciais com os responsáveis destas crianças, na EMEI, para apresentação e descrição da pesquisa e comprovação dos dados através da Caderneta de Saúde da Criança. Nesta fase, um dos sujeitos pré-selecionados foi excluído do estudo, pois, apesar de sua mãe ter referido que 0 mesmo havia nascido com oito meses de gestação, a Caderneta indicava 38 semanas de idade gestacional.

As outras 5 crianças prosseguiramno estudo, com consentimento dos responsáveis através daassinatura do Termo de Consentimento Livre e Esclarecido (TCLE). Na entrevista, foi aplicado um questionário direcionado aos pais, conforme descrito na Tabela 1.

Tabela 1 - Questionário direcionado aos pais

\begin{tabular}{c|c}
\hline Título pesquisado & Subitens \\
\hline Dados pessoais da criança & $\begin{array}{c}\text { Nome, endereço, telefone, sexo, data de nascimento, } \\
\text { nome da EMEl na qual estava matriculada e idade em que } \\
\text { começou a frequentá-la. }\end{array}$ \\
\hline Dados relacionados ao nascimento & $\begin{array}{c}\text { Idade gestacional, peso e estatura ao nascer, valores de } \\
\text { Apgar no } 1^{\circ} \text { e } 5^{\circ} \text { minutos, ocorrência de gemelaridade, local } \\
\text { de nascimento, tipo de parto e uso ou não de fórceps. }\end{array}$ \\
\hline Informações relevantes & $\begin{array}{c}\text { Intercorrências durante a gestação ou parto, tempo de } \\
\text { internação neonatal, presença de patologia relacionada } \\
\text { à prematuridade, realização de fisioterapia e/ou outros } \\
\text { tratamentos, e local onde a criança costuma permanecer } \\
\text { por maior tempo, quando está acordada. }\end{array}$ \\
\hline Dados sócio demográficos dos \\
familiares & $\begin{array}{c}\text { Idade, profissão e escolaridade dos pais, renda familiar, } \\
\text { meios de transporte utilizados, tipo de moradia e } \\
\text { componentes do grupo familiar. }\end{array}$ \\
\hline
\end{tabular}

A avaliação do DNPM dos sujeitos foi realizada nas EMEls, em horário pré-agendado, através do TTDD II, na própria sala e com colegas de sua convivência cotidiana para minimizar uma possível reação de estranhamento das crianças às pesquisadoras.

O TTDD II é um instrumento de triagem rápida, aplicado quando existe suspeita de atraso no desenvolvimento da criança ou há exposição a fatores de risco potenciais. Pode ser aplicado desde o nascimento até a idade de seis anos e é composto por 125 itens, divididos entre os setores pessoal/social, motor fino, linguagem e motor grosso. No presente estudo, foram avaliados somente os itens contemplados no setor de desenvolvimento motor grosso.

Primeiramente, foi obtida a idade corrigida da criança, ou seja, idade que ela teria se tivesse nascido com 37 semanas de gestação. Este cálculo é feito através da sua idade real (cronológica), subtraindo-se a diferença entre as 37 semanas e a idade gestacional que o bebê tinha quando nasceu ${ }^{17,18}$. A partir daí, através de estímulos das pesquisadoras, a criança foi submetida à realização de diversas tarefas para avaliar se suas habilidades motoras estavam condizentes com sua faixa etária.

No TTDD II, os itens avaliados são apresentados em forma de gráfico, e em cada marco do desenvolvimento podemos observar os respectivos limites mínimo e máximo da idade de aparecimento. Para aplicação do teste, traça-se uma linha vertical no eixo correspondente à idade corrigida da criança, percorrendo todos os itens do gráfico ${ }^{19}$.

Cada item é representado por um retângulo cujo limite esquerdo corresponde ao percentil 25 , ou seja, a idade em que $25 \%$ das crianças conseguem realizar a tarefa em questão, e o limite direito que corresponde ao percentil 90, ou seja, 
a idade em que $90 \%$ das crianças obtiveram sucesso na respectiva tarefa. 0 mesmo retângulo também apresenta os percentis 50 e 75 , representando a idade em que $50 \%$ e $75 \%$ das crianças realizaram aquele item, respectivamente. No lado esquerdo do retângulo, quando aparece a letra "R", significa que o item pode ser obtido através de relato dos pais ou responsáveis pela criança avaliada ${ }^{19}$.

O percentil 90 foi o ponto de corte utilizado no TTDD II para definir atraso (quando a criança não consegue realizar um item que fica totalmente à esquerda da linha da idade) ou cautela (quando a criança falha em um item que a linha da idade está entre os percentis 75 e 90). 0 teste classifica o desempenho da criança em normal (nenhum atraso e no máximo uma cautela) ou suspeito (duas ou mais cautelas e/ou um ou mais atrasos) ${ }^{19}$.

Após análise das avaliações do DNPM dos sujeitos, foi entregue pessoalmente uma carta aos pais informando os resultados de cada criança, juntamente com um folder personalizado (em duas vias - uma para os pais/cuidadores e outra para os educadores das EMEls) contendo sugestões de atividades e orientações de movimentos e exercícios em forma de brincadeiras que continuarão auxiliando a criança na construção das diferentes funções neuropsicomotoras e estimulando seu desenvolvimento de acordo com cada faixa etária.

Após a organização dos achados da avaliação, estes foram analisados e discutidos de modo descritivo, amparados na literatura científica atual. Alguns dados foram organizados em forma de tabela para melhor visibilidade.

\section{Resultados e discussão}

Os cinco sujeitos que compuseram a amostra tinham idades cronológicas entre 11 e 24 meses, na data da avaliação do DNPM, e suas características estão descritas na Tabela 2.

Tabela 2 - Caracterização da amostra

\begin{tabular}{c|c|c|c|c|c|c|c}
\hline Sujeito & Sexo & $\begin{array}{c}\text { IG* }^{*} \\
\text { (semanas) }\end{array}$ & $\begin{array}{c}\text { Peso ao } \\
\text { nascer } \\
\mathbf{( k g})\end{array}$ & $\begin{array}{c}\text { Estatura } \\
\text { ao nascer } \\
(\mathbf{c m})\end{array}$ & $\begin{array}{c}\text { Apgar } \\
\mathbf{1}^{\prime}\end{array}$ & $\begin{array}{c}\text { Apgar } \\
\mathbf{5}^{\prime}\end{array}$ & $\begin{array}{c}\text { Tipo de } \\
\text { parto }\end{array}$ \\
\hline Criança A & $\mathrm{F}$ & 34 & 2,635 & 46 & $-{ }^{* *}$ & 8 & Vaginal \\
\hline Criança B & $\mathrm{M}$ & 36 & 3,680 & 48,5 & 9 & 9 & Cesáreo \\
\hline Criança C & $\mathrm{F}$ & 36 & 3,575 & 49 & 8 & 9 & Cesáreo \\
\hline Criança D & $\mathrm{F}$ & 36 & 1,810 & 43 & 8 & 9 & Cesáreo \\
\hline Criança E & $\mathrm{F}$ & 36 & 3,200 & 48 & 9 & 9 & Vaginal \\
\hline
\end{tabular}

*: Idade Gestacional.

**: Não constava na Caderneta de Saúde da Criança.

Todas as crianças avaliadas nasceram de gestações únicas e sem a utilização de fórceps durante o parto. Segundo as entrevistas realizadas com os pais, nenhuma apresentava problema de saúde relacionado com o nascimento pré- termo.

A prematuridade pode ser classificada em limítrofe (entre 35 e 36 semanas de gestação), moderada (entre 31 e 34 semanas) e extrema (inferior ou igual a 30 semanas) ${ }^{20}$. A maior parte dos sujeitos da pesquisa são prematuros limítrofes, e apenas a criança A está classificada como prematuro moderado.

Com relação ao índice de Apgar, cabe ressaltar que, entre as crianças nascidas pré-termo, há maior incidência de ocorrer baixos valores, principalmente no quinto minuto ${ }^{21}$. Contudo, o presente trabalho não confirmou esta associação, pois todos os sujeitos apresentaram valores acima de 8, o que pode ser entendido como normal, com baixo risco de complicações futuras ${ }^{22,23,24}$.

As principais intercorrências, durante a gestação, referidas pelas mães foram descolamento de placenta e perda de líquido amniótico. A ruptura prematura das membranas amnióticas (RPM) é definida como a perda de líquido amniótico antes do início do trabalho de parto, independentemente da idade gestacional. A prevalência de RPM varia de 8 a 10\% de todas as gestações, e 2 a 4\% das rupturas ocorrem em gestações pré-termo. No Brasil, 30 a 40\% dos nascimentos prematuros estão associados com a RPM ${ }^{25}$. 0 descolamento prematuro de placenta (DPP) constitui-se na separação da placenta eutópica do seu sítio de implantação, variando desde pouco sintomático, com reduzido sangramento vaginal e pouca ou nenhuma consequência materno-fetal, até o descolamento completo, podendo ocasionar um parto prematuro, gerando possíveis complicações para a mãe e para o feto ${ }^{26}$. 
A idade das mães variou entre 23 a 35 anos, e dos pais entre 28 a 43 anos. Este dado contraria o que dizem alguns estudos, que apontam que os fatores para o nascimento de bebês pré-termo podem estar associados com gestações na adolescência ou mães com idade acima de 35 anos $^{4}$.

De acordo com o TTDD II, todos os sujeitos tiveram seu DNPM classificado como normal, apesar de algumas crianças terem falhado em determinadas habilidades motoras.

Tabela 3 - Resultados da avaliação do Desenvolvimento Neuropsicomotor (DNPM), a partir do Teste de Triagem de Desenvolvimento de Denver II (TTDD II).

\begin{tabular}{|c|c|c|c|c|c|}
\hline $\begin{array}{l}\text { Sujeitos } \\
\text { da } \\
\text { pesquisa }\end{array}$ & $\begin{array}{c}\text { Idade } \\
\text { cronológica }\end{array}$ & $\begin{array}{c}\text { Idade } \\
\text { Corrigida }\end{array}$ & Habilidades motoras esperadas & $\begin{array}{l}\text { Habilidades } \\
\text { motoras não } \\
\text { realizadas }\end{array}$ & $\begin{array}{c}\text { Classificação do } \\
\text { DNPM }\end{array}$ \\
\hline Criança $\mathrm{A}$ & $\begin{array}{c}1 \text { ano, } 4 \text { meses } \\
\text { e } 24 \text { dias }\end{array}$ & $\begin{array}{c}1 \text { ano, } 4 \text { meses } \\
\text { e } 3 \text { dias }\end{array}$ & $\begin{array}{l}\text { "Fica de pé sozinho", "inclina-se e } \\
\text { retorna", "anda bem", "anda para } \\
\text { trás", "corre", "sobe degraus" e } \\
\text { "chuta bola para frente". }\end{array}$ & $\begin{array}{l}\text { Todas foram } \\
\text { executadas }\end{array}$ & Normal \\
\hline Criança B & $\begin{array}{c}11 \text { meses e } 17 \\
\text { dias }\end{array}$ & $\begin{array}{c}11 \text { meses e } 10 \\
\text { dias }\end{array}$ & $\begin{array}{l}\text { "Fica de pé apoiado", "puxa para } \\
\text { ficar de pé", "passa para sentado", } \\
\text { "fica de pé - } 2 \text { segundos", "fica de } \\
\text { pé sozinho", "inclina-se e retorna" e } \\
\text { "anda bem". }\end{array}$ & $\begin{array}{l}\text { "Fica de pé - } 2 \\
\text { segundos", "fica } \\
\text { de pé sozinho", } \\
\text { "inclina-se e } \\
\text { retorna" e "anda } \\
\text { bem". }\end{array}$ & Normal \\
\hline Criança C & $\begin{array}{c}2 \text { anos e } 17 \\
\text { dias }\end{array}$ & - * & $\begin{array}{l}\text { "Anda para trás", "corre", "sobe } \\
\text { degraus", "chuta bola para frente", } \\
\text { "pula" e "joga bola de cima para } \\
\text { baixo". }\end{array}$ & "Pula". & Normal \\
\hline Criança D & $\begin{array}{c}1 \text { ano, } 3 \text { meses } \\
\text { e } 27 \text { dias }\end{array}$ & $\begin{array}{c}1 \text { ano, } 3 \text { meses } \\
\text { e } 20 \text { dias }\end{array}$ & $\begin{array}{l}\text { "Fica de pé sozinho", "inclina-se e } \\
\text { retorna", "anda bem", "anda para } \\
\text { trás", "corre" e "sobe degraus". }\end{array}$ & $\begin{array}{l}\text { "Anda para } \\
\text { trás". }\end{array}$ & Normal \\
\hline Criança $\mathrm{E}$ & $\begin{array}{c}1 \text { ano, } 6 \text { meses } \\
\text { e } 16 \text { dias }\end{array}$ & $\begin{array}{c}1 \text { ano, } 6 \text { meses } \\
\text { e } 9 \text { dias }\end{array}$ & $\begin{array}{l}\text { "Inclina-se e retorna", "anda bem", } \\
\text { "anda para trás", "corre", "sobe } \\
\text { degraus", "chuta bola para frente" e } \\
\text { "joga bola de cima para baixo". }\end{array}$ & $\begin{array}{l}\text { Todas foram } \\
\text { executadas }\end{array}$ & Normal \\
\hline
\end{tabular}

*: Neste caso, não é necessário corrigir a idade, pois isto só deve ser feito até os 24 meses. ${ }^{4}$

De acordo com a literatura, a partir do $13^{\circ}$ mês, os Msls ficam próximos entre si na posição ortostática e na posição agachada, permitindo uma variedade de movimentos à criança e refletindo a maior habilidade no equilíbrio ${ }^{15,27}$. Estas habilidades também apareceram na avaliação do DNPM da criança $A$.

A criança B obteve sucesso nos três primeiros itens, porém falhou nos restantes. Mesmo assim, seu DNPM foi considerado normal, pois apenas uma falha ocorreu em um item em que mais de $75 \%$ das crianças da sua idade conseguem realizar (ficar de pé por dois segundos). As outras três habilidades que ele não realizou, menos de $50 \%$ das crianças da sua idade também não realizam ${ }^{19}$. Segundo diversos pesquisadores do desenvolvimento infantil, a partir do $11^{\circ}$ mês a criança desenvolve a habilidade de equilibrar-se, tornando-se mais estável em ortostase e andando segurado por uma mão; por vezes pode abandonar 0 apoio e dar alguns passos livremente, ainda que com insegurança $a^{11,15,27,28}$. Portanto, a criança $B$ já poderia ficar de pé sozinha, apesar de a não realização deste item não ser considerado atraso no DNPM, segundo o TTDD II.

Quanto à avaliação da criança $C$, o item que ela não conseguiu realizar, $50 \%$ das crianças da sua idade também não o fazem ${ }^{19}$. A aquisição de habilidades locomotoras (como correr e saltar) e de controle de objetos (lançar e receber uma bola) parecem ser fundamentais para todo o desenvolvimento motor posterior. Assim, apesar desta criança não apresentar atraso no DNPM, o domínio dessas habilidades é uma das mais importantes tarefas do início da infância, pois crianças que não desenvolvem de maneira eficiente seus padrões de movimento poderão ter dificuldades de adquirir níveis aceitáveis de desenvolvimento em ações motoras futuras ${ }^{29}$.

Segundo o TTDD II, o item em que a criança D obteve falha é realizado por mais de $75 \%$ das crianças na sua idade ${ }^{19}$. Ao contrário do que diz o teste, estudos anteriores afirmam que é só a partir do $16^{\circ}$ mês que a criança desenvolve capacidades para variações do caminhar, podendo deslocar-se de lado, para trás e na ponta dos pés ${ }^{11,15,27,28}$. 
A criança $E$ obteve sucesso em todos os itens avaliados. Isto confirma o que dizem alguns autores, que até $018^{\circ}$ mês, a criança já realiza marcha independente, já pode segurar um objeto em cada mão enquanto caminha, consegue subir escadas com ajuda e vencer obstáculos ${ }^{15,27}$.

A criança A ingressou na EMEI com 14 meses de idade, as crianças B e C com 4 meses, e as crianças $D$ e $E$ com 6 meses. Não existe um consenso quanto à influência das instituições de Educação Infantil no DNPM das crianças. Alguns autores afirmam que uma EMEI de boa qualidade pode ser uma boa oportunidade para beneficiar o desenvolvimento infantil, na medida em que estas instituições devem realizar um trabalho de forma planejada, com espaços adequados no sentido de estimular o processo de desenvolvimento motor, cognitivo, emocional e social das crianças, além do cuidado e atenção às suas necessidades básicas ${ }^{30,31}$. Por outro lado, outros apontam que essas instituições podem representar um risco ao bom desenvolvimento das crianças, já que o ambiente físico mais pródigo, como uma linda escola de educação infantil repleta de brinquedos, pode não ser suficiente, se contar com uma equipe que não seja dedicada e atenciosa, com pessoas carinhosas e que ofereçam bons estímulos às crianças ${ }^{32,33,34}$. Neste estudo, sugere-se que as EMEls possam ter influenciado positivamente, já que todos os sujeitos apresentaram DNPM normal, e mais da metade deles ingressou na instituição até os 6 meses de idade.

Todos os pais referiram que o chão era o local da casa onde as crianças permaneciam por mais tempo, enquanto acordadas. Esta informação é importante, uma vez que se sabe que a interação da criança com seu ambiente oferece ótimas experiências sensório-motoras. Alguns pais costumam retirar todos os objetos que julgam estar atrapalhando o filho ou proporcionando riscos, e tendem a superprotegê-los, o que os impede de explorar o ambiente em busca de novas habilidades. O lar oferece riscos ao bebê assim como muitos outros ambientes, mas estes devem ser medidos e trabalhados de maneira que a criança não fique restrita e possa interagir com seu meio, auxiliando no treino de equilíbrio e na evolução para aquisição do engatinhar e da marcha ${ }^{5,9,12,14}$.

Em um estudo realizado em 2012, com o objetivo de avaliar as alterações existentes no desenvolvimento motor de bebês a partir de orientações aos pais e cuidadores em um programa interventivo de fisioterapia no contexto familiar, participaram vinte e dois bebês, divididos em dois grupos: grupo interventivo (GI) e grupo controle (GC). Os grupos foram avaliados no início e no fim de oito semanas. Muitas crianças eram privadas socialmente e culturalmente por sua família (cuidadores) de envolver-se com outras crianças, ou permaneciam restritas a seus berços, cadeirinhas de alimentação, colo e andador infantil. Durante o período do programa, bebês do GC utilizaram andador infantil e alguns eram restritos ao leito ou carrinho, ao contrário dos do $\mathrm{Gl}$, que, devido às atividades do programa, tinham maior liberdade para brincar e eram orientados sobre a não utilização de andadores. Observou-se significância no desenvolvimento motor no GI do pré para o pós-intervenção $(\mathrm{p}=0,029)$. Os resultados sugerem que bebês, quando estimulados de maneira correta em ambiente familiar, desenvolvem maior qualidade em seu aprendizado motor ${ }^{12}$.

Quanto à escolaridade das mães, duas possuíam Ensino Médio (EM) e três, Ensino Superior (ES) completos. E quanto aos pais, três haviam concluído o EM e dois, o ES. Este dado corrobora com vários outros estudos que afirmam que 0 grau de escolaridade dos pais influencia o DNPM de seus filhos ${ }^{8,9,12}$.

Em geral, quanto mais baixo o peso ao nascimento, maior o risco de um desenvolvimento neurológico aquém do idea| $\left.\right|^{6,7,7,10,30,35}$. De uma forma geral, neonatos com peso inferior a 2.500 gramas são considerados de baixo peso ao nascimento, inferior a 1.500 gramas, de muito baixo peso, e abaixo de 1.000 gramas, de peso extremamente baixo ao nascer. No presente estudo, apenas a criança D nasceu com $1810 \mathrm{~g}$, porém esta variável não interferiu no seu DNPM, até a data da avaliação. Em outra pesquisa, acompanhando prematuros sem doença clínica aguda ou neurológica, também não se observou influência da idade gestacional ou do peso ao nascimento na aquisição dos padrões motores avaliados por outra escala de desenvolvimento infantili ${ }^{36}$.

Apesar de os bebês prematuros apresentarem maior risco de atraso no DNPM que aqueles nascidos a termo, não há um consenso definido sobre as alterações neuropsicomotoras e os déficits apresentados por essas crianças a longo prazo $0^{8,37,38}$.

Uma pesquisa foi realizada com crianças nascidas prematuramente, com idades entre 1 e 17 meses, que não apresentavam nenhuma malformação ou patologias genéticas. Os bebês foram avaliados através do TTDD II, antes e depois da realização de oito encontros em grupos de educação em saúde, abordando assuntos ligados ao desenvolvimento do bebê. Os sujeitos foram divididos em Grupo 1 (participantes dos encontros) e grupo 2 (grupo controle). Os dados encontrados neste estudo referente ao desenvolvimento motor grosso mostraram que o Grupo 1 manteve o número de falhas e cuidado e houve um aumento significativo do número de acertos. Já no Grupo 2, notou-se um aumento do número de falhas e atrasos ${ }^{5}$. 
Um estudo observacional e longitudinal tinha amostra constituída pelo Grupo Pré-termo (GPT), de crianças nascidas com IG $\leq 34$ semanas e peso $\leq 1500 \mathrm{~g}$, e pelo Grupo Controle (GC), de nascidos a termo (IG $\geq 37$ semanas e peso $\geq$ $2500 \mathrm{~g}$ ), pareados por sexo e idade corrigida ao GPT. As crianças foram avaliadas aos 12, 15 e 18 meses, com correção de idade para o GPT. Observou-se que as crianças pré-termo andaram mais tardiamente. Estes resultados dão suporte às evidências de que crianças pré-termo apresentam escores mais baixos em testes motores no segundo ano de vida, 0 que parece ter impacto no desempenho funcional, especialmente na marcha e na habilidade de autocuidado. Estímulos ambientais mais limitados no GPT podem ter influenciado esses resultados, potencializando o risco biológico associado à prematuridade. Sabe-se que fatores biológicos têm grande influência sobre o desenvolvimento no primeiro ano de vida, mas, a partir do segundo, os fatores ambientais ganham maior relevância. O presente estudo permite concluir que crianças nascidas com IG inferior a 34 semanas e peso $<1500 \mathrm{~g}$, mesmo quando não se observam sequelas neurológicas evidentes, mostram atraso motor e funcional no segundo ano de vida?.

Vários fatores podem influenciar o desenvolvimento do bebê antes, durante e após o nascimento. $O$ fato de a criança estar incluída em alguns dos itens de risco não significa, necessariamente, que ela irá apresentar problemas futuros. Em uma avaliação do desenvolvimento motor de crianças matriculadas em creches públicas no município de Joaçaba (SC), a única criança prétermo e de baixo peso, apresentou um desenvolvimento motor excelente. Contudo, ela deve receber um acompanhamento diferenciado ao longo do seu desenvolvimento para que possíveis alterações possam ser identificadas precocemente ${ }^{37,38}$.

Por isso, elaborou-se um folder para os pais/cuidadores e um para os educadores da EMEI de cada criança, com exemplos de movimentos e exercícios em forma de brincadeiras que auxiliam na construção das diferentes funções neuropsicomotoras, favorecendo o seu relacionamento com ela mesma e com o meio que a cerca. As orientações foram escritas de acordo com a idade da criança, conforme o Quadro 1. A criança $A$ recebeu orientações referentes à faixa etária dos 16 meses aos 3 anos; a criança $B$, dos 10 a 24 meses; a criança $C$, dos 2 aos 5 anos; a criança $D$, dos 13 meses aos 3 anos; e a criança $E$, dos 18 meses aos 4 anos. Os folders continham o cálculo da idade corrigida (exceto a criança $\mathrm{C}$, que tinha mais de 2 anos) e figuras ilustrando as orientações descritas.

Quadro 1 - Orientações aos pais, cuidadores e educadores

\begin{tabular}{|c|c|}
\hline $\begin{array}{c}\text { Faixa Etária } \\
\text { (meses) }\end{array}$ & Orientações \\
\hline 10 a 12 & $\begin{array}{l}\text { 1- Nesta fase os jogos de encaixe são importantes, pois oferecem várias experiências e conceitos para as crianças; } \\
\text { mas o adulto deve estar junto, auxiliando quando necessário e conversando sobre os tamanhos, formas e cores dos } \\
\text { objetos. Estas brincadeiras também são importantes para estimular a motricidade fina da criança. } \\
\text { 2- Deixe que a criança se movimente segurando-se nos móveis ou apoiada pela mão, e ao mesmo tempo } \\
\text { incentive-a a dar alguns passos sem apoio. }\end{array}$ \\
\hline 13 a 15 & $\begin{array}{l}\text { 1- No verão, estimule a criança a ficar de pés descalços e experimentar diferentes tipos de solo } \\
\text { (grama, areia, tapetes, madeira, etc). } \\
\text { 2- Estimule a criança a estar junto com outras pessoas (crianças ou adultos), evitando deixá-la somente no } \\
\text { "chiqueirinho", em casa, ou apenas no berço observando as outras crianças, na EMEl. } \\
\text { 3- O uso do andador convencional deve ser evitado, pois não auxilia na aprendizagem do caminhar, já que os pés } \\
\text { da criança não ficam totalmente apoiados no chão e o esforço que ela faz para se locomover é bastante inferior ao } \\
\text { que seria necessário sem o uso do equipamento. A criança pode até demorar mais para começar a ficar em pé e } \\
\text { andar sem apoio, e ainda pode começar a andar na ponta dos pés. } \\
\text { 4- Uma boa opção nesta fase é o uso de andadores de empurrar, que ajudam a criança a desenvolver a habilidade } \\
\text { de andar naturalmente, porém sempre com a supervisão de um adulto. }\end{array}$ \\
\hline 16 a 18 & $\begin{array}{l}\text { 1- Permita que a criança se suje ao brincar, pois experimentar e conviver (com pessoas, lugares, animais, } \\
\text { plantas ou objetos) é fundamental para seu desenvolvimento motor e psicossocial. } \\
\text { 2- Bola é sempre um bom brinquedo, pois oferece uma grande variedade de movimentos ao } \\
\text { chutar, jogar para outra pessoa, passar de mão em mão, etc. } \\
\text { 3- Não pegue a criança no colo quando precisar subir ou descer escadas; } \\
\text { segure-a pela mão e deixe-a fazer com suas próprias pernas. } \\
\text { 4- Para estimular a motricidade fina da criança, permita e ajude-a nas atividades de montar e empilhar objetos. } \\
\text { coordenação motora da criança também são muito importantes. }\end{array}$ \\
\hline
\end{tabular}

Continua... 


\begin{tabular}{|c|c|}
\hline $\begin{array}{c}\text { Faixa Etária } \\
\text { (meses) }\end{array}$ & Orientações \\
\hline 19 a 24 & $\begin{array}{l}\text { 1- Estimule o uso da colher independentemente. } \\
\text { 2- Ensine a tirar meias, sapatos e roupas simples. } \\
\text { 3- Quando passear com ela, fale sobre as coisas que veem, nomeando os objetos, cores, formas e lugares. } \\
\text { 4- Ofereça um ou mais cestos e bolinhas para lançar dentro deles. } \\
\text { 5- Amarre um barbante ou corda entre dois bancos e ou cadeiras, um palmo acima do chão } \\
\text { e ensine a criança a passar por cima. Segure-a pela mão para que não perca o equilíbrio. } \\
\text { Quando conseguir fazer, estimule-a para que repita a atividade sozinha. }\end{array}$ \\
\hline 25 a 36 & $\begin{array}{l}\text { 1- Deixe a criança participar de algumas atividades da casa, como ajudar a arrumar a mesa do jantar, por exemplo. } \\
\text { 2- Converse muito com a criança e, quando ela falar algo errado, repita a palavra certa para que grave o correto. } \\
\text { 3- Combine com a criança que o chão da sala é o mar, e que vocês não podem cair nele. Espalhe algumas } \\
\text { almofadas, tapetinhos ou papéis para servirem de "ilhas" para que vocês consigam passar de um lugar para o } \\
\text { outro sem "molhar" o pé. É uma brincadeira divertida que colabora para o senso de equilíbrio e de consciência de } \\
\text { espaço. Teste o caminho antes para ver ser não há perigo de a criança escorregar. }\end{array}$ \\
\hline 37 a 48 & $\begin{array}{l}\text { 1- Nessa fase, a criança descobre seus heróis favoritos e adora usar fantasias, fingir ser outra pessoa. } \\
\text { Proponha teatrinhos, fantoches, jogos de dramatização e simulação, onde ela pode usar } \\
\text { sua criatividade para representar personagens. } \\
\text { 2- Desenhar, pintar e modelar com argila ou massinha são excelentes brincadeiras que } \\
\text { ajudam a estimular a criatividade e a motricidade fina. } \\
\text { 3- É preciso ficar atento e deixar a própria criança descobrir naturalmente se é destra ou canhota. } \\
\text { Forçá-la a usar uma das mãos para escrever, comer ou se pentear pode influenciar negativamente no } \\
\text { eu aprendizado causando sérios problemas, principalmente na alfabetização. }\end{array}$ \\
\hline 49 a 60 & $\begin{array}{l}\text { 1- Nesta fase, a criança gosta de participar de jogos em que precisa seguir regras. } \\
\text { Por exemplo, o jogo de dominó - em que só pode juntar peças com quantidades iguais; na amarelinha - em que } \\
\text { precisa esperar sua vez e não pode pular pisando na linha. } \\
\text { É bom os adultos jogarem com ela. Assim, podem, pelo exemplo, ensinar a ela a conviver bem, } \\
\text { respeitando os outros. } \\
\text { 2- Ensine e estimule a criança a usar a tesoura (de preferência sem ponta). } \\
\text { 3- Experimente diferentes brincadeiras com corda, para aprimorar sua coordenação motora. } \\
\text { 4- Leia histórias curtas, cante músicas e converse sempre com a criança sobre sua rotina, dando atenção às } \\
\text { perguntas e respondendo-as sempre de forma que a criança entenda o que está sendo falado. }\end{array}$ \\
\hline
\end{tabular}

Fonte: Bobath e Bobath ${ }^{11}$; Ratliffe ${ }^{15}$; Saccani27; Vega et $\mathrm{al}^{28}$.

Assim, embora este estudo tenha demonstrado que nenhum dos sujeitos avaliados apresentava atraso no desenvolvimento, é importante que os pais, cuidadores e educadores continuem provendo os estímulos necessários para que estas crianças sigam com o DNPM adequado à sua faixa etária.

\section{Considerações Finais}

Sabe-se que o DNPM nos primeiros anos de vida influencia o restante do crescimento e as habilidades adquiridas pela criança ao longo do tempo. Assim, a Fisioterapia tem a responsabilidade de contribuir com pesquisas relacionadas ao desenvolvimento infantil, especialmente as referentes à evolução da motricidade, tanto em crianças saudáveis quanto nas expostas a fatores de risco.

A presente pesquisa demonstrou que as crianças avaliadas não apresentaram atraso no seu DNPM. Porém, sugerese que outros trabalhos deem continuidade a este estudo, avaliando os mesmos sujeitos futuramente, em outras fases de seu desenvolvimento, para averiguar se os fatores de risco ligados à prematuridade não terão influência em longo prazo.

Salienta-se que todas as habilidades motoras presentes na avaliação do DNPM foram insistentemente testadas, não deixando dúvidas quanto à realização ou não dos referidos itens do TTDD II. Porém, neste estudo, foram analisados somente itens contidos no setor de desenvolvimento motor grosso. Para uma análise ainda mais abrangente, sugere-se que sejam testados também os demais setores contemplados pelo TTDD II. 


\section{Referências Bibliográficas}

1. Unicef (Brasil). Pesquisa para estimar a prevalência de nascimentos pré-termo no brasil e explorar possíveis causas. Pelotas [internet]. 2013 [acesso 2014-09-29. Disponível em: http://www.unicef.org/brazil/pt/br_prematuridade_possiveis_causas.pdf 2. Ministério da Saúde (Brasil), Portal da Saúde. Brasília, DF [internet]. 2012 [acesso 2014-08-16]. Disponível em: http:// portalsaude.saude.gov.br/index.php/cidadao/principal/agencia-saude/noticias-anteriores-agencia-saude/1793-

3. Bonilha ALL, Porciuncula MB, Espirito Santo LC, Pedron CD, Romero MM. Prematuridade tardia: O pré natal das mães destes recém-nascidos no sistema único de saúde. In: SENPE, 170, 2013, Natal. Anais do evento. Porto Alegre [internet]. 2012 [acesso 2014-10-31]. Disponível em: http://www.abeneventos.com.br/anais_senpe/17senpe/pdf/0665co.pdf

4. Rangel TC, Mathias AERA, Rocha LCD, Castro RKA. Elaboração e aplicação do manual para familiares de lactentes pré-termo que apresentam atraso do desenvolvimento. Rev Participação, 21:8-14, 2012.

5. Spíndola BM, Rodrigues F, Moreira J, Tuon L. A utilização de grupos de educação em saúde no desenvolvimento motor de bebês prematuros. Rev. Saúde Públ., 1:7-21, 2013.

6. Borba EM, Rodrigues F, Fagundes F, Dalpizol L, Duarte S, Silva ES. A influência do baixo peso ao nascer sobre os reflexos primitivos de recém-nascidos. Revista Cippus - Unilasalle, 2:185-200, 2012.

7. Rocha SR, Dornelas LF, Magalhães LC. Instrumentos utilizados para avaliação do desenvolvimento de recém-nascidos pré-termo no Brasil: revisão da literatura. Cad. Ter. Ocup., 1:109-117, 2013.

8. Garcia PA, Vieira MEB, Formiga CKMR, Linhares MBM. Influência de fatores de risco no desenvolvimento neuromotor de lactentes pré-termo no primeiro ano de vida. Revista Movimenta, 2:83-98, 2011.

9. Souza ES, Magalhães LC. Desenvolvimento motor e funcional em crianças nascidas pré-termo e a termo: influência de fatores de risco biológico e ambiental. Rev Paul Pediatr, 4:462-470, 2012.

10. Rocha SHS, Moraes JFVN, Ramos IA, Rauber SB, Pereira LA, Simões HG, Campbell CSG. Desenvolvimento motor e sua influência em testes de leitura e psicogênese de escolares. Saúde (Santa Maria), 1:91-98, 2014.

11. Bobath B, Bobath K. Desenvolvimento motor nos diferentes tipos de paralisia cerebral. Tradução de Dra. Elaine Elisabetsky. 1.ed. São Paulo: Manole; 1989.

12. Oliveira SMS, Almeida CS, Valentini NC. Programa de fisioterapia aplicado no desenvolvimento motor de bebês saudáveis em ambiente familiar. Rev. Educ. Fís/UEM, 1:25-35, 2012.

13. Venturella CB, Zanandrea G, Saccani R, Valentini NC. Desenvolvimento motor de crianças entre 0 e 18 meses de idade: Diferenças entre os sexos. Revista Motricidade, 2:3-12, 2013.

14. Padilha JF, Seidel EJ, Copetti F. Análise do desenvolvimento motor e qualidade do ambiente domiciliar de crianças pré-escolares. Saúde (Santa Maria), 1:99-108, 2014.

15. Ratliffe KT. Fisioterapia na clínica pediátrica: guia para a equipe de fisioterapia. 1.ed. São Paulo: Santos; 2000.

16. Goldim JR. Manual de iniciação à pesquisa em saúde. 2.ed. rev. ampl. Porto Alegre: Dacasa; 2000.

17. Restiffe AP. $O$ desenvolvimento motor dos recém-nascidos pré-termos nos primeiros seis meses de idade corrigida segunda Alberta Infant Motor Scale: um estudo de coorte [dissertação]. São Paulo: Universidade de São Paulo, Faculdade de Medicina; 2004. [acesso 2014-09-21]. Disponível em: http://www.teses.usp.br/teses/disponiveis/5/5160/tde-10052006-110014/.

18. Rugolo LMSS. Crescimento e desenvolvimento a longo prazo do prematuro extremo. Jornal de Pediatria, 1:101-110, 2005. 19. Frankenburg WK, Dodds JB, editors. Denver II technical manual. Denver: Denver Developmental Materials Inc.; 1990.

20. Czechowski AE, Fujinaga $\mathrm{Cl}$. Seguimento ambulatorial de um grupo de prematuros e a prevalência do aleitamento na alta hospitalar e ao sexto mês de vida: contribuições da Fonoaudiologia. Rev Soc Bras Fonoaudiol, 4:572-577, 2010. 21. Melo, WA, Carvalho MDB. Análise Multivariada dos fatores de riscos para Prematuridade no Sul do Brasil. Revista Eletrônica Gestão \& Saúde, 2:398-409, 2014.

22. Alencar RL. Ventilação Mecânica em neonatos: Fatores predisponentes e implicações clínicas [monografia]. Campina Grande: Universidade Estadual da Paraíba; 2013. [acesso 2014-09-05. Disponível em: http://dspace.bc.uepb.edu. br:8080/xmlui/bitstream/handle/123456789/5227/PDF\%20-\%20Rayanne\%20Limeira\%20Alencar.pdf?sequence=1

23. Kilsztajn S, Lopes ES, Carmo SN, Reyes AMA. Vitalidade do recém-nascido por tipo de parto no Estado de São Paulo, Brasil. Cad. Saúde Pública, 8:1886-1892, 2007.

24. Sardinha LMV. Mortalidade infantil e fatores associados à atenção à saúde: estudo caso-controle no Distrito Federal (20072010) [tese]. Brasília: Universidade de Brasília; 2014. [acesso 2014-09-05]. Disponível em: http:///hdl.handle.net/10482/16396 
25. Patriota AF, Guerra GVQL, Souza ASR. Ruptura prematura das membranas antes da 35a semana: resultados perinatais. Rev Bras Ginecol Obstet, 7: 296-302, 2014.

26. Vitória KM, Ennes LO, Tavares RF, Araújo ICO, Zwetkoff BF, Reis AS, Oliveira G et al. Descolamento prematuro de placenta: relato de caso. Rev Med Minas Gerais, 2:58-60, 2011.

27. Saccani R. Validação da alberta infant motor scale para aplicação no brasil: análise do desenvolvimento motor e fatores de risco para atraso em crianças de 0 a 18 meses [dissertação] [internet]. Porto Alegre: Universidade Federal do Rio Grande do Sul; 2009. [acesso 2014-08-24]. Disponível em: www.bibliotecadigital.ufrgs.br/ da.php?nrb=000733746\&loc $=2010 \& \mid=4753 d 757 b 9721263$

28. Vega JM, Luque A, Sarmento GJV, Moderno LFO. Tratado de fisioterapia hospitalar: assistência integral ao paciente. São Paulo: Atheneu; 2012.

29. Oliveira DS, Oliveira IS, Cattuzzo MT. A influência do gênero e idade no desempenho das habilidades locomotoras de crianças de primeira infância. Rev Bras Educ Fís Esporte, 4:647-655, 2013.

30. Araujo LB. Análise do desenvolvimento neuropsicomotor de crianças de zero a três anos em centros de educação infantil [dissertação]. Curitiba: Universidade Federal do Paraná; 2013. [acesso 2014-09-21]. Disponível em: http://hdl.handle.net/1884/30434 31. Winkelmann ER, Trento GZ, Bonamigo ECB. Avaliação do Desenvolvimento Neuropsicomotor de Crianças de Escolas de Educação Infantil de ljuí/Rs. Revista Contexto \& Saúde, 15:31-36, 2008.

32. Belsky J. Desenvolvimento Humano: experenciando o ciclo da vida. Tradução de Daniel Bueno. Porto Alegre: Artmed; 2010. 33. Leite FF, Mendonça GAF, Costa MPM. Analise do Desenvolvimento Neuropsicomotor de crianças semiinstitucionalizadas em Creches [Trabalho de conclusão de Curso - Graduação. Belém: Universidade da Amazônia; 2009. [acesso 2014-09-21]. Disponível em: www.unama.br/novoportal/ensino/graduacao/cursos/fisioterapia/attachments/ article/131/analise_desenvolvimento_psicomotor_criancas.pdf

34. Willrich A, Azevedo CCF, Fernandes JO. Desenvolvimento motor na infância: influência dos fatores de risco e programas de intervenção. Rev Neurocienc., 1:51-56, 2009.

35. Monteiro RCS, Aragão VMF, Lamy ZC, Silva FMAM, Silva ELC, Silva MS et al. Vivências lúdicas de pré-escolares nascidos com muito baixo peso. Rev Pesq Saúde, 1:16-23, 2012.

36. Manacero S. Desempenho motor de prematuros durante o primeiro ano de vida na Escala Motora Infantil de Alberta (AIMS) [dissertação]. Porto Alegre: Pontifícia Universidade Católica do Rio Grande do Sul; 2005. [acesso 2014-09-05]. Disponível em: tede2.pucrs.br/tede2/bitstream/tede/1815/1/395299.pdf

37. Salbego GS, Gerzson LR, Antunes VP, Pasin JSM. Intervenção precoce em neonatos de risco. In: FÓRUM EM FISIOTERAPIA, 3., 2012, Santa Maria. Anais do evento. Santa Maria [internet]. 2011 [acesso 2014-09-05]. Disponível em: http://www.unifra.br/eventos/forumfisio/Trabalhos/5174.pdf

38. Martinello M, Nazario PF, Marques LZ, Ries LGK, Lando C. Avaliação do desenvolvimento motor de crianças matriculadas em creches públicas. HU Revista, 2:155-162, 2011.

\section{Gleizy Berticelli}

Endereço para correspondência - Rua: Augusto Spengler, $n^{\circ} 500$ - Bloco 6, Ap 402, Bairro: Universitário, CEP: 96815-654, Santa Cruz do Sul, RS, Brasil.

E-mail: gleizy@gmail.com

Lattes: http://lattes.cnpq.br/6163990232072466

Cinara Freitas Henker - cinarahenker@hotmail.com

Patrícia Oliveira Roveda - roveda.patricia@gmail.com

Valéria Neves Kroeff Mayer - lelafisio@ibest.com.br

Enviado em 11 de janeiro de 2015. Aceito em 10 de agosto de 2015. 